\title{
GeoScience Engineering
}

\section{USE OF POLYMERIC ENERGY ABSORPTION LINERS TO IMPROVE THE CONCRETE ROCK FALL BARRIERS}

\author{
Eren KÖMÜRL ̈̈ (D) \\ Giresun University, Department of Civil Engineering, Giresun, Turkey \\ E-mail: erenkomurlu@gmail.com
}

\begin{abstract}
In this study, usability of polymer foam coatings on impact surfaces of concrete rock fall barriers to increase the energy absorption capacity performances was investigated with a series of experimental studies. For this purpose, impact tests were carried out on different concrete block samples within the laboratory tests. According to the results, it was determined that the displacement values of the barrier blocks due to the impact effect can be significantly reduced by using polymer energy absorption liners. Additionally, cracks and failures of the concrete block bodies resulting from high impact energies can be prevented by the polymer energy absorption liners. It was assessed that a polyurethane based thermoset foam coating with a density of $60 \mathrm{~kg} / \mathrm{m} 3 \mathrm{can}$ economically and remarkably improve the concrete barriers against impact loads.
\end{abstract}

Keywords: Concrete barriers; Energy absorption capacity; Rock fall barriers; Rock falls.

\section{INTRODUCTION}

It is possible to use concrete barriers on the slope sides of roads to prevent the damages of the rock falls. In addition to the roads, rigid concrete barriers can be placed at the bottom of the slopes to prevent damage to the structures. Falling rock blocks cause an impact load on the barriers. Depending on the energy level of that dynamic (impact) loading, concrete barriers can be broken and/or have significant displacements. In this context, the friction capacity at the bottom of concrete blocks and the energy absorption capacity of the concrete block bodies are the main parameters for the performance of rock fall barriers. The amount of impact energy acting on the barriers depends on various factors such as the falling height, frictions during the fall, the rock block weight and its geometric shape [1-3]. A schematic drawing shown of the rock fall barrier use is given in Figure 1.

Big volumes of rock blocks falling from a high height cause high levels of the impact energy. The concrete barriers should have the ability to absorb the rock fall energy in order to prevent damages and losses. Therefore, it is important to design proper rock fall barriers considering the site characteristics. As a significant disadvantage, concrete materials have relatively low impact strengths resulting from their brittle material properties [4-6]. Because of having poor impact energy absorption capacities, concrete barrier bodies can severely fail as basically shown in Figure 2. 


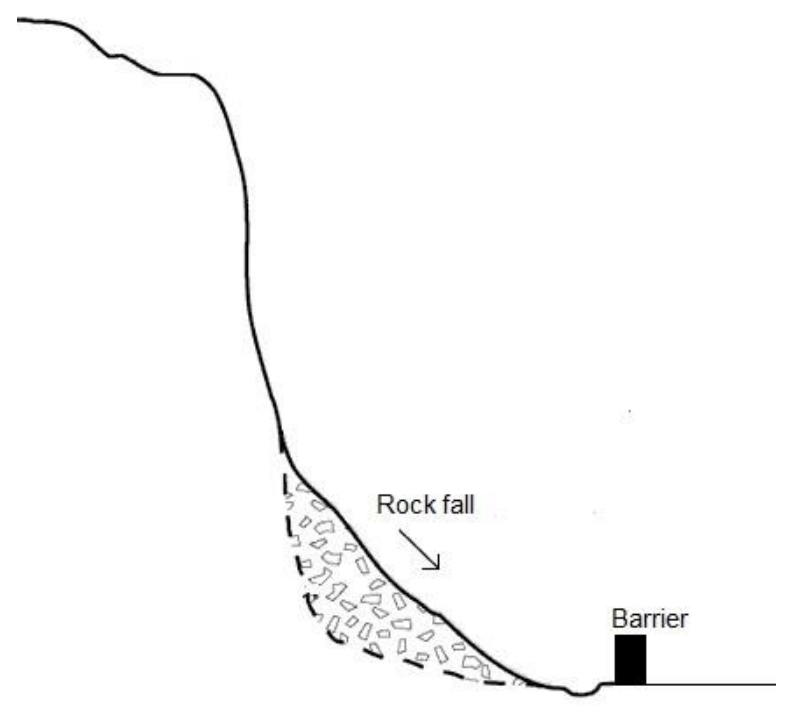

Figure 1. A schematic shown of the rock fall barrier usage

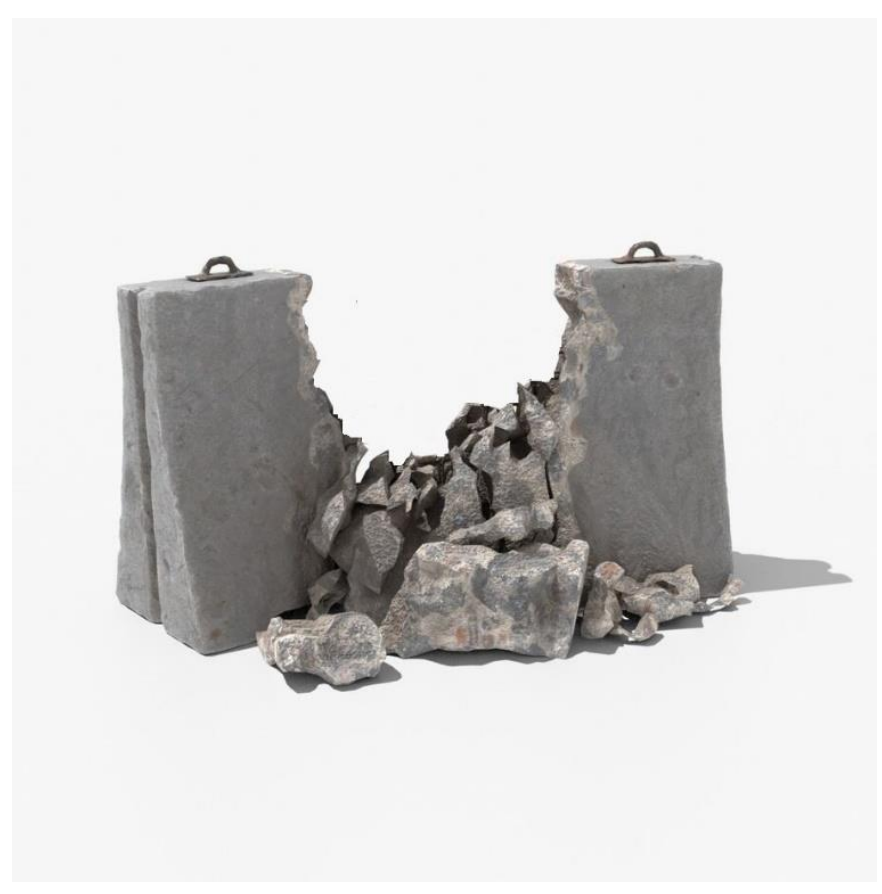

Figure 2. An illustration of concrete barrier body failure [7]

The use of polymer materials has become popular in solving many engineering problems. Similarly, the use of new engineering polymers is also becoming widespread in rock engineering applications [8-11]. As a result of the high energy absorption capacities of polymer materials, they can be advantageous especially in applications where the impact load occurs.

Thermosets, a group of polymer materials, polymerize owing to contact of their liquid components. The thermosets can have one, two or more components. Thermosets, whose components are supplied in liquid phase before the polymerization, can be used practically in surface coating applications. Solidification times of the thermoset products can vary within a wide range, depending on the self-properties and production details. Liquid components 
of thermosets should be mixed well before their polymerization reactions for a good chemical reaction performance. Solidification on the surface is an important advantage in coating processes in terms of taking roughness shapes and providing a good contact [12-14]. The components which generally have high viscosities can be coated in several layers for thick liner applications.

In this study, a polyurethane type thermoset polymer material was used to coat the impact surfaces of the concrete block samples. Polyurethane is an isocyanate-based copolymer and nowadays used for many different kinds of insulation applications such in buildings, tanks, pools and waste deposition plants, because of its good resistivity against the seasonal and environmental changes. Polyurethane foams are also used for different purposes in the geotechnical engineering works [15-18]. The scope of this study is to investigate whether the polyurethane foam coat is effective for improvement of the impact energy absorption capacities of the concrete block barriers, or not.

The stress-strain curves of polymeric foams under the compressive loading case have three definite regions which are called linear elastic, plateau and densification regions (Figure 3). The polyurethane foams are quite ductile materials that densification continues instead of failure even under very high strain levels over $60 \%$ [4]. Because of its deformability property, the polyurethane foam material was selected for the aim of supplying a good energy absorption capacity to improve the impact resistivity of the barriers.

Polyurethane polymerizes owing to the chemical reaction between the liquid ingredients called polyol and isocyanate. The polyurethane foams can be divided into three groups according to their densities, as light foams $\left(<80 \mathrm{~kg} / \mathrm{m}^{3}\right)$, mid-density foams $\left(80-180 \mathrm{~kg} / \mathrm{m}^{3}\right)$ and dense foams $\left(>180 \mathrm{~kg} / \mathrm{m}^{3}\right)$. As a motivation of this study, it has been predicted that the cracking or failure of the concrete block bodies can be prevented because of the impact energy absorption by the polymer coating. It has been also tested with a series of experimental studies to investigate whether the polymer liner can reduce the sliding displacements of the barriers by absorbing the impact load. It can be noted that the polymer liner effect on two main topics of slide and body failure resistivities was investigated within this study. Detailed information about the experimental methodology is given under the next title. Evaluating the findings from this study in consideration of the polymer liner material costs, the affordability of the polyurethane foam type coat for improving rock fall barrier performances was examined within this study.

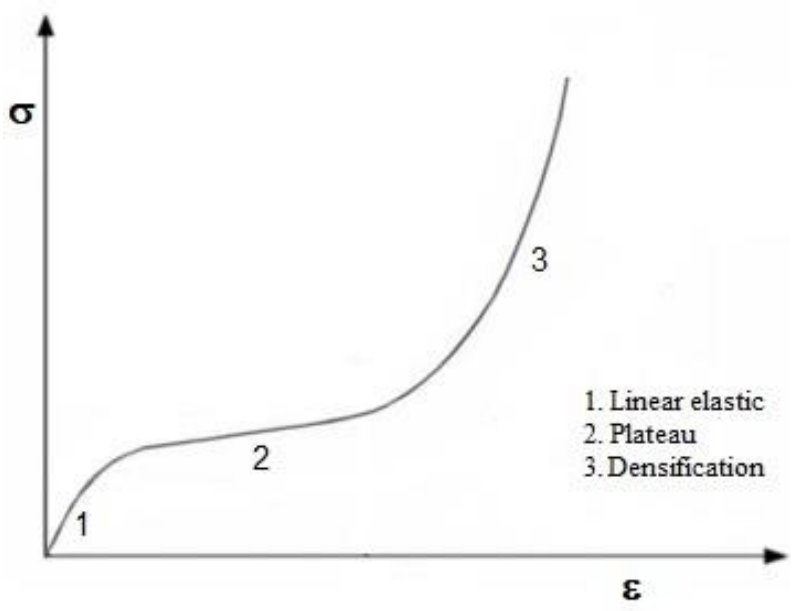

Figure 3. Typical stress strain behavior of polyurethane rigid foams

\section{METHODOLOGY}

Within this study, precast concrete blocks with $30 \mathrm{~cm}$ x $20 \mathrm{~cm}$ x $15 \mathrm{~cm}$ sizes were used as the laboratory scale samples. For making a comparison to assess the barrier performances, the size of the concrete bodies was the same for both samples with and without the polymer coating. All the concrete blocks used in this study have same content and been fabricated from the same mix. The impact load acting on the barrier blocks was modelled with the Charpy test setup. In the Charpy experimental setup, the potential energy turns into the kinetic energy when the hammer falls from a certain height, and the hammer hits the samples creating an impact loading. The energy level of the hammer which depends on the arm height can be read from the indicator on the setup. The Charpy test 
equipment used in this study is shown in Figure 4. Concrete blocks were placed on a base rock slab. Before and after the hammer blow, the boundaries of the concrete blocks were marked on the base slab for determination of the amount of sliding displacements resulting from the impact effect. Depending on the hammer arm drop height and hammer weight, the amount of energy in the Charpy impact test can vary. $150 \mathrm{~J}$ energy level which is half of the setup capacity was acted in the slide test to only make displacement without cracking. In the body failure test, the impact energy of $300 \mathrm{~J}$ was acted on samples.

Totally, 10 specimens were used in the block slide test and 5 of them were coated by using the polymer layer. Only impact surfaces of the blocks were coated by the polymeric foam layer which is used to absorb the dynamic energy. There are three stages of polyurethane foam polymerization. In the first stage called as cream time, polymerization reaction does not start and the mix of the components is in the liquid form. Typical cream times for polyurethane foams change from 5 to 240 seconds. The product used in this study has a cream time of 120 seconds, which is a period to conveniently cover the surfaces by performing different methods like pouring or spraying. By the end of the gel time, the polymerization and frothing start in the second stage. Then, foam material solidifies completely and the polymerization ends at the end of the third stage called as tack free time. The maximum mechanical strength is reached at the end of the tack free time varying between 18 hours and 24 hours for most of the polyurethane foams.

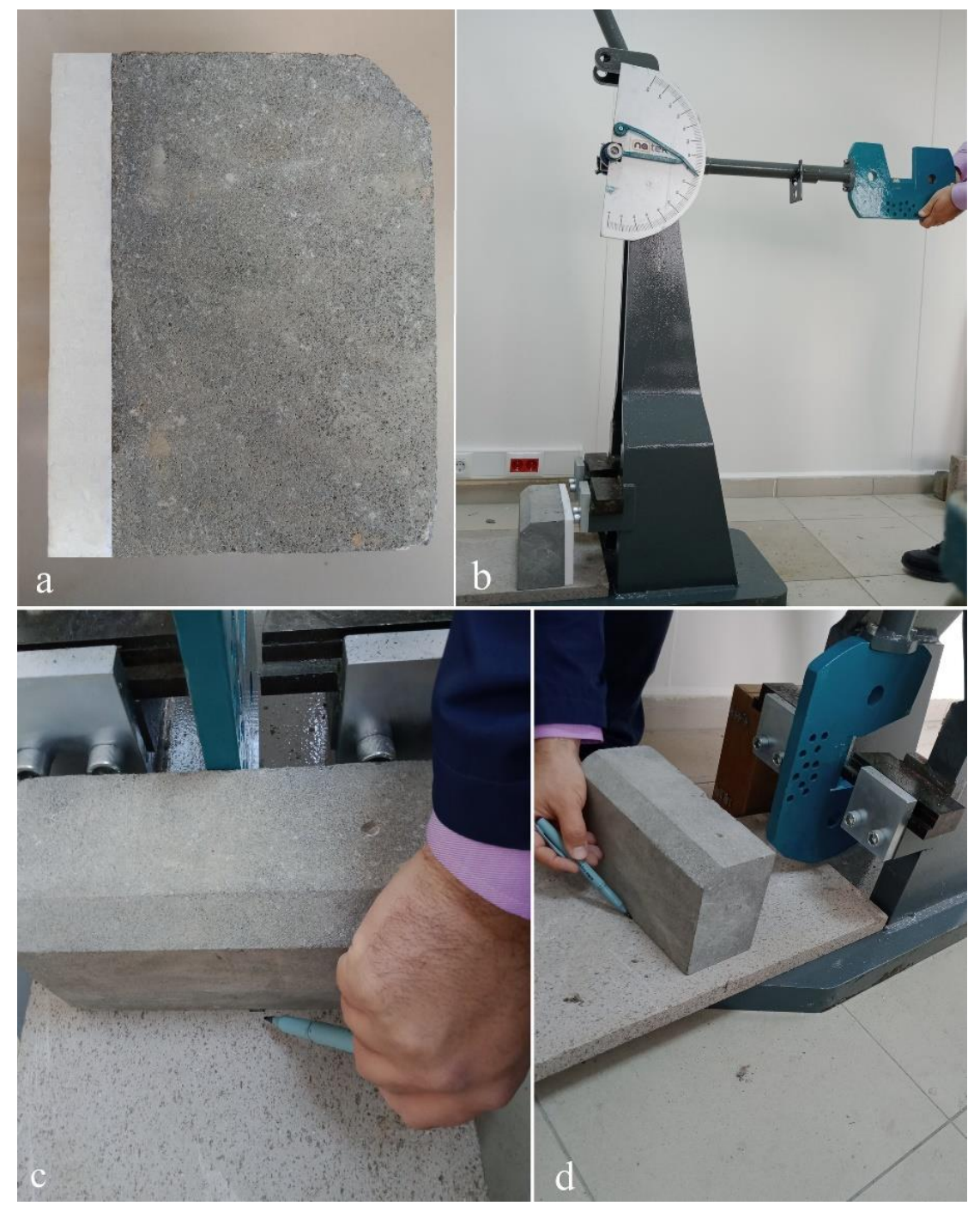

Figure 4. Slide test: a) Polyurethane liner coating on the concrete block, b) hammer lift and drop, c) concrete position marking before the hammer drop, d) block position marking after sliding due to the impact effect 
The density of the polymer foam product used in this study is $60 \mathrm{~kg} / \mathrm{m}^{3}$ after the end of the tack free time. The liquid mix of the components can be poured and spread on the block surfaces within the gel time of the product. Because of the polymerization process, the foam liner thicknesses increase to a level which depends on the frothing ratio. As another way, polymerized foam layers can be cut and glued on the blocks for the liner coating purpose. For appropriately using same liner thickness on the samples, foam layers with the thickness of $2 \mathrm{~cm}$ were cut and glued on the concrete blocks by using a cyanoacrylate adhesive in this study.

In addition to the slide test, the failure of the body was also examined within the scope of this study. After the slide tests, concrete blocks were supported in the Charpy equipment to examine a failure that can occur in the concrete body because of the hammer blow. Since sliding is prevented in the supported specimens, the energy transferred to the blocks caused cracking in the concrete body. In order to examine cracking in the concrete body, block samples with a relatively thin thickness were used in the body failure tests. The dimensions of the concrete blocks used in the body failure test are $20 \mathrm{~cm} \times 12 \mathrm{~cm} \times 9 \mathrm{~cm}$. The blocks were placed on the sample abutment part of the equipment. As the hammer hits to a specimen, an amount of energy is consumed for the breakage. To measure the energy consumption amount, the height difference between the initial position and which the pendul um rises after failure is recorded by a pointer mounted on the dial (Figure 5). The Charpy impact test is an immediate load test that determines the amount of energy absorption during the fracturing of a sample. It has a simple formula to determine the energy absorption capacity (EAC). The energy amount read on the dial of the equipment can be calculated by using a simple formula as given in Equation 1 .

$$
E A C=m g\left(h_{1}-h_{2}\right)
$$

where $m$ is the mass of the hammer, $g$ is gravitational acceleration, $h_{l}$ is height of hammer before the drop and $h_{2}$ is the hammer height raised after the sample failure.

\section{RESULTS AND DISCUSSIONS}

Results obtained from this experimental study are given in Tables 1 and 2. As seen from Table 1, the slide (displacement) resistivity of the concrete blocks was found to be significantly improved by the use the polymer foam layer. As a result of using only $2 \mathrm{~cm}$ thickness of the liner, the displacement values of the blocks could be nearly halved. Additionally, the impact energy absorption capacities of the block bodies can be remarkably improved as a result of using the polymer layer. The polymer layer supplied $95 \%$ increase in the impact energy absorption capacity of the block bodies.

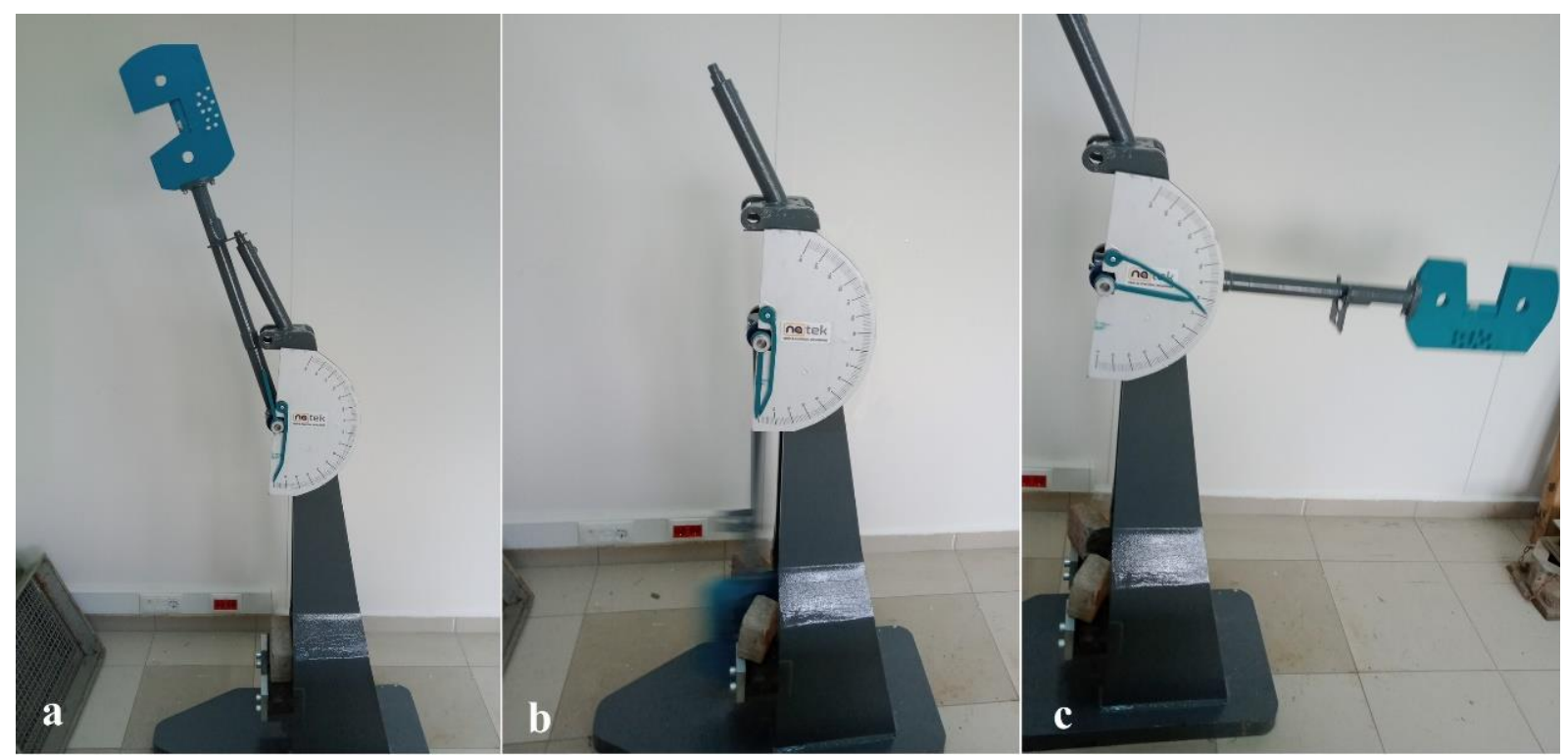




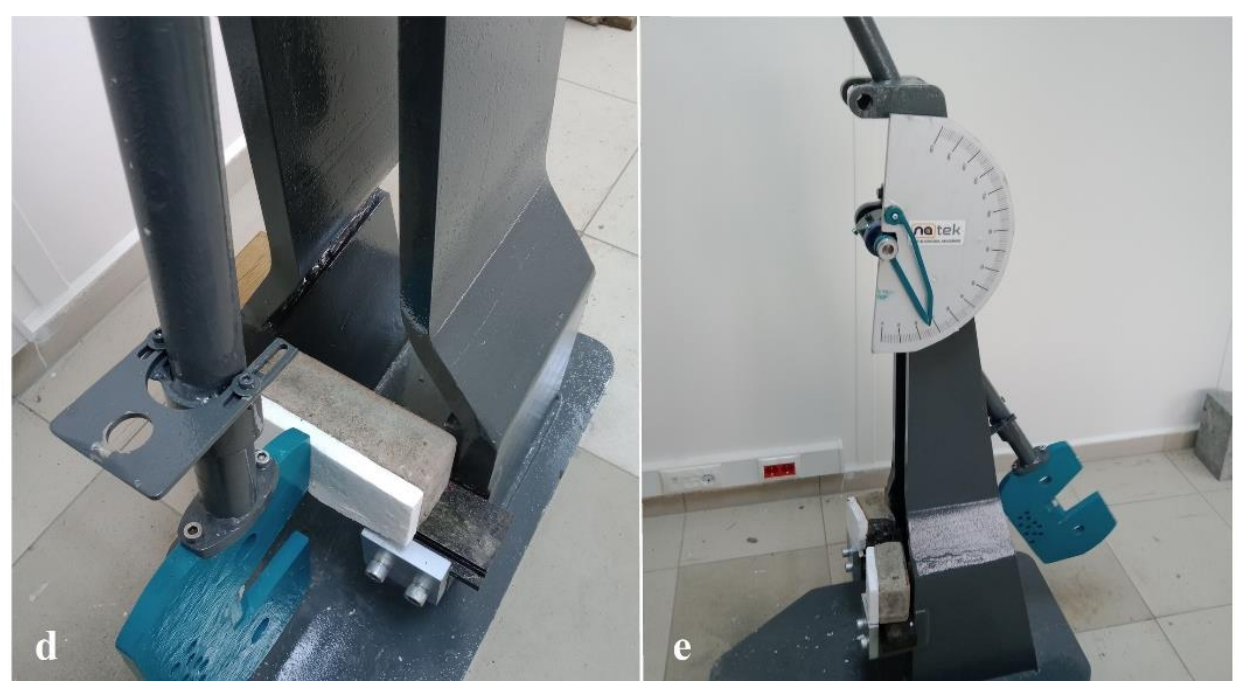

Figure 5. Body failure test: a) Hammer position before the drop, $b$ and c) failure of a specimen without the polymer liner, d) impact hammer contact, e) failure of a specimen with the polymer liner

Table 1. Slide test results (BPC: Block samples with polymer coating, BNC: Block samples with no polymer coating, SN: Specimen number, SD: Standard deviation)

\begin{tabular}{|c|c|c|c|}
\hline Specimen type & SN & $\begin{array}{c}\text { Mean displacement } \\
(\mathbf{c m})\end{array}$ & $\begin{array}{c}\text { SD for Mean displacement } \\
(\mathbf{c m})\end{array}$ \\
\hline BPC & 5 & 6 & 1 \\
\hline BNC & 5 & 11 & 2 \\
\hline
\end{tabular}

Table 2. Body failure test results (EAC: Energy absorption capacity)

\begin{tabular}{|c|c|c|c|}
\hline Specimen type & SN & EAC (J) & SD for EAC (J) \\
\hline BPC & 5 & 256 & 13 \\
\hline BNC & 5 & 131 & 8 \\
\hline
\end{tabular}

It was assessed that the load acting on the slide surface at the bottom can be decreased as a result of the significant energy absorption of the polymer layer on the impact surface. Therefore, polymer coatings supplied relatively less slide displacements than those of the concrete blocks without the energy absorption liner. Also, it was assessed that the damages in the concrete body can be prevented by the energy absorbing polymer layers.

Since polymers are deformable materials, they have much higher energy absorption capacities compared to concrete materials [19-21]. Concrete materials need to be improved because of its lacks resulting from some issues like having brittle material characteristics, low tensile strength values, etc. To overcome the problems of concrete materials, composite material technologies and new engineering polymers can be used for various practices in rock engineering [22-24]. Especially, the use of polymeric materials seems to be more popular in rock engineering in last years. Within this study, it was found that polymer materials are also advantageous as surface liners for the rock fall barriers.

The cost of the polymer liner material is 2.2 USD per a $\mathrm{m}^{2}$ for the thickness of $2 \mathrm{~cm}$. Considering its significant energy absorption capacity improvement, that cost can be assessed to be affordable. In the field works, liner thicknesses can be selected higher than those in this laboratory scale study for a better increase in the performances of the concrete barriers. 
It should be noted herein that many different polymer layer materials can be investigated to assess their effect on the performances of the concrete rock fall barriers in further studies. Following the progressions in the polymer science and technology, it is possible to select more effective and economical liners in the future works. Many problem solutions from past to present of the rock engineering have been realized as a result of the use of new materials [25-28]. Therefore, it will be highly beneficial for rock engineers to test new materials. With the use of

right materials, many more important advances can be made in rock engineering.

\section{CONCLUSION}

According to the results obtained from this study, following research findings can be noted as conclusion matters:

1. The energy absorption liners made of the polyuretha ne foam type polymer material are advantageous in terms of displacement limitations of the concrete rock fall barriers.

2. Polymeric energy absorption liners are also usable to remarkably increase the impact strength of the concrete barrier body.

3. The polymeric energy absorption liners are beneficial in improving the performance of concrete barriers. Various polymer products can be investigated within further studies on their use with the rock fall barriers.

\section{REFERENCES}

[1] TOE, D., A. MENTANI, L. GOVONI, F. BOURRIER, G. GOTTARDI and S. LAMBERT. Introducing Meta-models for a More Efficient Hazard Mitigation Strategy with Rockfall Protection Barriers. Rock Mechanics and Rock Engineering. 2020, vol. 51, pp. 1097-1109. ISSN 1434-453X. DOI: 10.1007/s00603017-1394-9

[2] YU, Z.X., L. ZHAO, Y.P. LIU, S.C. ZHAO, H. XU and S.L. CHAN. Studies on flexible rockfall barriers for failure modes, mechanisms and design strategies: a case study of Western China. Landslides. 2019, vol. 16, pp. 347-362. ISSN 1612-5118. DOI: 10.1007/s10346-018-1093-y

[3] LAMBERT, S., D. TOE, A. MENTANI and F. BOURRIER. A Meta-Model-Based Procedure for Quantifying the On-Site Efficiency of Rockfall Barriers. Rock Mechanics and Rock Engineering. 2021, vol. 54, pp. 487-500. ISSN 1434-453X. DOI: 10.1007/s00603-020-02298-7

[4] KÖMÜRLÜ, E. An Investigation of Foam Concrete Usability as a Cavity Filler Material in Mining. GeoScience Engineering. 2021. vol. 67(3), pp. 77-84. ISSN 1802-5420. DOI: 10.35180/gse-2021-0054

[5] SOLOMON, A. and G. HEMALATHA. Characteristics of expanded polystyrene (EPS) and its impact on mechanical and thermal performance of insulated concrete form (ICF) system. Structures. 2020, vol. 23, pp. 204-213. ISSN 2352-0124. DOI: 10.1016/i.istruc.2019.10.019

[6] NAGENDRAN, S.K. and M.A.M. ISMAIL. Analysis of Rockfall Hazards Based on the Effect of Rock Size and Shape. International Journal of Civil Engineering. 2019, vol. 17, pp. 1919-1929. ISSN 2383-3874. DOI: 10.1007/s40999-019-00418-1

[7] Free3D [online]. New Orleans: TurboSquid, Inc. 2021 [cit. 2021-10-31]. Available from: https://free3d.com

[8] KÖMÜRLÜ, E. High-density polyurethane rigid foam usability as liner support material in rock engineering. Arabian Journal of Geosciences. 2020, vol. 13, art no. 422. ISSN 1866-7538. DOI: 10.1007/s12517-02005396-6

[9] WANG Y., J. FENG, J. LI, B. LAI and T. YANG. Advance of FRP anchor bolts in geotechnical anchoring. Journal of Engineering Geology. 2018, vol. 26(3), pp. 776-784. DOI: 10.13544/j.cnki.jeg.2017-139

[10] BARLA, G. Full-face excavation of large tunnels in difficult conditions. Journal of Rock Mechanics and Geotechnical Engineering. 2016, vol. 8(3), pp. 294-303. ISSN 1674-7755. DOI: 10.1016/j.jrmge.2015.12.003

[11] WANG, Z.-N., S.-L. SHEN, A. ZHOU and H.-M. LYU. Experimental investigation of water swelling characteristics of polymer materials for tunnel sealing gasket. Construction and Building Materials. 2020, vol. 256, art no. 119473. ISSN 0950-0618. DOI: $10.1016 /$ j.conbuildmat.2020.119473

[12] LI, Z., B. NOCELLI and S. SAYDAM. Effect of rock strength and surface roughness on adhesion strength of thin spray-on liners. International Journal of Rock Mechanics and Mining Sciences. 2017, vol. 91, pp. 195-202. ISSN 1365-1609. DOI: 10.1016/j.ijrmms.2016.11.011 
[13] OZTURK, H. and D. TANNANT. Influence of rock properties and environmental conditions on thin sprayon liner adhesive bond. International Journal of Rock Mechanics and Mining Sciences. 2011, vol. 48(7), pp. 1196-1198. ISSN 1365-1609. DOI: $10.1016 /$ i.ijrmms.2011.06.006

[14] OZTURK, H. Work of Adhesion of Thin Spray-On Liners. Rock Mechanics and Rock Engineering. 2012, vol. 45, pp. 1095-1102. ISSN 1434-453X. DOI: 10.1007/s00603-012-0238-X

[15] CHEN, Q., R. YU, Y. LI, G. TAO and S. NIMBALKAR. Cyclic stress-strain characteristics of calcareous sand improved by polyurethane foam adhesive. Transportation Geotechnics. 2021, vol. 31, art. no. 100640. ISSN 2214-3912. DOI: 10.1016/j.trgeo.2021.100640

[16] SALEH, S., K. AHMAD, N.Z. MOHD YUNUS and M.A. HEZMI. Evaluating the toxicity of polyurethane during marine clay stabilisation. Environmental Science and Pollution Research. 2020, vol. 27, pp. 21252 21259. ISSN 1614-7499. DOI: 10.1007/s11356-020-08549-y

[17] KÖMÜRLÜ, E. and A. KESIMAL. Experimental study of polyurethane foam reinforced soil used as rocklike material. Journal of Rock Mechanics and Geotechnical Engineering. 2015, vol. 7(5), pp. 566-572. ISSN 1674-7755. DOI: 10.1016/j.jrmge.2015.05.004

[18] MA, W., W. GAO, S. GUO, Y. ZHAO, Z. WU and C. YANG. Evaluation and improvement on the freezethaw durability performance of the polyurethane stabilized Pisha sandstone for water and soil conservation. Cold Regions Science and Technology. 2020, vol. 177, art. no. 103065. ISSN 0165-232X. DOI: 10.1016/j.coldregions.2020.103065

[19] SHAH, S.A.A., M.A.A. GUL, T. NAQASH, Z. KHAN and M. RIZWAN. Effects of Fiber Reinforcements on the Strength of Shotcrete. Civil Engineering and Architecture. 2021, vol. 9(1), pp. 176-183. ISSN 23321121. DOI: $10.13189 / \mathrm{cea} .2021 .090115$

[20] KÖMÜRLÜ, E., A. KESIMAL and S. DEMIR. Spraying Membrane Layer Effect on Load Bearing Performance of Concrete Liners. In: European Rock Mechanics Symposium 2016 (EUROCK 2016): August 29-31, 2016, Cappadocia, Turkey. 2016, pp. 715-719.

[21] ZHANG S., Y. WANG, Y. TONG, Y. CHEN, Z. LI and D. NIU. Flexural toughness characteristics of basalt fiber reinforced shotcrete composites in high geothermal environment. Construction and Building Materials. 2021, vol. 298, art. no. 123893. ISSN: 0950-0618. DOI: 10.1016/j.conbuildmat.2021.123893

[22] YAO, D., G. QIAN, J. LIU and J. YAO. Application of Polymer Curing Agent in Ecological Protection Engineering of Weak Rock Slopes. Applied Sciences. 2019, vol. 9(8), art. no. 1585. ISSN 2076-3417. DOI: 10.3390/app9081585

[23] KÖMÜRLÜ, E. An Investigation of Using Thermoset Polymer Type Liquid Additives to Improve Cement Grout Performances in Rock Bolting Applications. International Journal of Geosynthetics and Ground Engineering. 2020, vol. 6, art. no. 52. ISSN 2199-9279. DOI: 10.1007/s40891-020-00236-9

[24] KESEJINI, Y.A., A. BAHRAMIFAR, H. AFSHIN and M.E. TABRIZI. High Deformable Concrete (HDC) element: An experimental and numerical study. Advances in Concrete Construction. 2021, vol. 11(5), pp. 357-365. ISSN 2287-531X. DOI: 10.12989/acc.2021.11.5.357

[25] KÖMÜRLÜ, E. and A. KESIMAL. Experimental Study on Usability of Friction Rock Bolts with Plastic Bodies. International Journal of Geomechanics. 2017, vol. 17(9). ISSN 1943-5622. DOI: 10.1061/(ASCE)GM.1943-5622.0000960

[26] ZHAO, Z., H. XIE, T. LIU and Y. WU. In Situ Curing of a Polymer Film for Light-Proof Coring of Deep Rocks with Preservation of Rock Quality and Moisture. Advances in Civil Engineering. 2020, vol. 2020, art. no. 8843779. ISSN 1687-8094. DOI: $10.1155 / 2020 / 8843779$

[27] PLESSIS, M.D. and D.F. MALAN. Investigating the use of polymer-modified cementitious thin spray-on liners as stope face support. International Journal of Rock Mechanics and Mining Sciences. 2021, vol. 142, art. no. 104728. ISSN 1365-1609. DOI: 10.1016/j.ijrmms.2021.104728

[28] VOGEL, F., R. SOVJÁK and Š. PEŠKOVÁ. Static response of double shell concrete lining with a sprayapplied waterproofing membrane. Tunnelling and Underground Space Technology. 2017, vol. 68, pp. 106112. ISSN 0886-7798. DOI: $\underline{10.1016 / j . t u s t .2017 .05 .022}$ 